
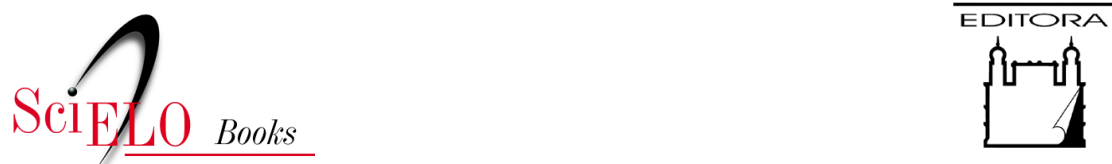

FIOCRUZ

\title{
4. "Tem fratura exposta? Artéria babando?" A perspectiva dos profissionais da saúde
}

\author{
Armelle Giglio-Jacquemot
}

\section{SciELO Books / SciELO Livros / SciELO Libros}

GIGLIO-JACQUEMOT, A. "Tem fratura exposta? Artéria babando?": a perspectiva dos profissionais da saúde. In: Urgências e emergências em saúde: perspectivas de profissionais e usuários [online]. Rio de Janeiro: Editora FIOCRUZ, 2005, pp. 57-74. Antropologia e Saúde collection. ISBN: 978-85-7541-378-4. https://doi.org/10.7476/9788575413784.0006.

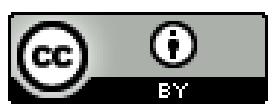

All the contents of this work, except where otherwise noted, is licensed under a Creative Commons Attribution 4.0 International license.

Todo o conteúdo deste trabalho, exceto quando houver ressalva, é publicado sob a licença Creative Commons Atribição 4.0.

Todo el contenido de esta obra, excepto donde se indique lo contrario, está bajo licencia de la licencia Creative Commons Reconocimento 4.0. 


\section{"Tem Fratura Exposta? Artéria Babando?": a perspectiva dos profissionais da saúde}

\section{UrGÊNCIA/EMERGÊNCIA: UMA DISTINÇÃO FAMILIAR}

Os médicos, enfermeiros e residentes que atuam no pronto-socorro se referem, com recorrência, à distinção entre urgência e emergência. Em nossas conversas, e mesmo quando não interrogados a seu respeito, eles insistiam muito sobre a importância dessa distinção, chegando, por exemplo, a classificar espontaneamente os casos por eles relatados na categoria das 'urgências' ou das 'emergências'. Já vimos, aliás, o quanto essa discriminação se faz presente na fala dos profissionais da saúde quando, lamentando a ignorância da população, criticam sua incapacidade de diferenciar essas duas categorias de urgências. Eis alguns trechos que exemplificam a referência comum a essa distinção nos discursos:

Oitenta, oitenta e cinco e até noventa por cento não são urgências. A criança vomitou uma vez, ou ela tem um pouco de febre, a mãe já leva para o PS. A população não distingue a urgência da emergência. A gente diz para ela vir quando a criança está com febre. Mas para eles a criança tem uma febrezinha, um $39^{\circ}$, é urgente. Para mim, médico, a febre é um sinal de alerta que pode se tornar um sinal de urgência se ela vem acompanhada com vômitos. (Médico atuando na triagem clínica infantil)

Tem que distinguir a urgência relativa, que são nove dos dez casos que atendi desde de manhã, da urgência absoluta. A urgência absoluta não é emergência. A urgência relativa pode se transformar em uma urgência absoluta que pode vir a ser uma emergência. Tem uma diferença entre as três. (Médico do pronto-socorro)

Urgência são os casos que necessitam ser atendidos, mas sem risco de vida. Emergência são os casos com risco de vida iminente. (Médica do pronto-socorro)

Uma criança com bronquite, cansada, cianose de lábios: é uma urgência. Um baleado, alguém sangrando, um acidente: é uma emergência. Os dois podem vir a morrer. Mas, no caso da criança, sabemos o que ela tem, ela respira normalmente. Enquanto o baleado, não sabemos o que ele tem, não sabemos a repercussão do que ele tem. Se os dois chegarem juntos, atendo primeiro a 
emergência e segundo a urgência. Começamos pelo pior. Certo que o que fica bom pode se tornar pior. (...) Se fosse o meu pai e o meu filho, porque é assim que todos fazem aqui, se eu vejo que meu pai está muito ruim e meu filho melhor, escolho atender primeiro o meu pai. Mas se vejo que o estado do meu filho está também muito ruim, ai eu cuido do meu filho. Opção para quem tem mais chance de sobreviver. (Médico do pronto-socorro)

Falta de ar na linguagem popular, na linguagem médica é dispnéia, é uma urgência, até uma emergência. Desmaio, se for em criança, para mim, é uma urgência, pois a criança não finge. Já no adulto não diria a mesma coisa, eles fingem, dissimulam. (Médico do pronto-socorro)

Na gineco a maior parte não é urgência (...). O parto é uma urgência, até uma emergência. Pode não ser, mas como não tem leito, se torna urgência. Agora, na ortopedia, tudo é urgência porque não se sabe se for fratura. (Residente do pronto-socorro)

Emergência é assim: o paciente chegou, inconsciente, tem uma escala de Glasgow, quando é inferior a 8 é que o paciente precisa de uma emergência. Tem que fazer todas as manobras, até fibrilação. Agora a urgência, por exemplo, tem um acidente, o paciente chega com ferimentos leves, não tem fratura, artéria babando. E tem o eletivo que é 80\% [dos casos]. É febre, dor de garganta, no dedo, na cabeça, contusão, torção. (...) Cólica renal, epilepsia, depende do exame que vai ser feito. A cólica renal pode ser um cálculo pequeno e já acabou. Nesse caso, ela é eletivo. Mas pode ser pielonefrite que pode ser aguda. Isso é emergência porque vai para a cirurgia. A gente segue uma linha assim no atendimento às emergências. Acidentado A, B e C. 'A'é desobstrução de vias áreas superiores. A prioridade é o ar. Ventilou, então pode esperar. (...) O paciente quer a prioridade para uma febre. Não sabe o que é emergência. Na sala de espera eles aguardam e acham que é demais. Não conseguem entender. (Enfermeira do pronto-socorro)

A freqüência e a facilidade com que os profissionais da saúde recorrem à distinção entre urgência e emergência testemunha sua familiaridade - característica ${ }^{1}$ - com essas noções e com sua discriminação apresentada como crucial. Urgências e emergências não devem ser confundidas: na avaliação dos estados/situações de saúde e, conseqüentemente, para a realização de atendimentos adequados, é fundamental saber fazer a diferença entre as duas, isto é, saber identificar os casos que 'não podem esperar' e os que 'podem esperar', segundo fórmulas muito usadas pelos próprios médicos e enfermeiros, pois, este é o grande traço diferenciador entre as emergências e as urgências, mesmo se as falas apontam também para diversas variáveis que, extraclínicas, têm incidência sobre essa apreciação (O paciente é uma criança ou é um adulto? É um jovem ou um velho? Tem leitos ou não tem? O prognóstico é favorável ou não?).

Existe um amplo consenso em torno da distinção a ser feita entre essas duas categorias de urgências. Entre os profissionais da saúde, são pouquíssimos os que a colocam abertamente em questão ou, pelo menos, que a discutem. No pronto-socorro estudado, dois médicos mostraram-se críticos. Apesar de partirem de um raciocínio diferente, os dois ficavam inconformados, e até indignados, com essa discriminação 
que julgavam absurda, do ponto de vista do sentido, e condenável, do ponto de vista ético. Representativos das críticas dirigidas a essa distinção, seus argumentos merecem ser examinados.

Fiel à etimologia das palavras, o dr. 1 estima que 'urgência' e 'emergência' não podem constituir duas categorias de urgências na medida em que aquilo que caracteriza uma emergência - que seja um sintoma, um acidente, um estado de saúde - não é sua gravidade, a necessidade de agir sem demora, mas o caráter súbito de sua ocorrência. Ora, o que se manifesta ou acontece repentinamente não apresenta necessariamente um caráter urgente, isto é, não representa ou assinala uma ameaça para a vida que exige uma intervenção médica imediata, como é o caso, por exemplo, de uma dor aguda que se manifesta de maneira inesperada. Nesse sentido, nem toda emergência é urgente.

Da mesma maneira, se a urgência exige uma ação terapêutica indispensável e rápida, ela não necessariamente apresenta um caráter súbito. Nesse sentido, uma urgência pode existir sem emergência, mesmo que apresentando um caráter de extrema gravidade. Por essas razões, a distinção urgência/emergência não tem sentido e não vale para discriminar as urgências do ponto de vista da gravidade, do tempo para agir, da prioridade do atendimento: só se deveria falar em urgências. Na concepção defendida pelo dr. 1, a emergência não caracteriza um grau (alto) de urgência, pois entre a primeira e a segunda não existe relação necessária.

O dr. 2 se mostra ainda mais severo e radical na crítica que, aí, vira denúncia. Expressão da prepotência dos médicos, a distinção urgência/emergência não só é insensata, mas também perigosa. Eis alguns trechos de sua fala:

Não tem sentido a diferença, acho que tem que ser uma palavra só, é impossivel, desnecessário e inconseqüente essa diferenciação entre emergência e urgência (...). Se imaginar um acidente com crash, tudo é emergente porque... se num acidente automobilistico com pessoas, o primeiro está conversando, até ajudando o atendimento, esse primeiro é considerado ótimo, mas ele pode estar com uma lesão hepática e sangrando. E o segundo, um paciente sem sentidos - ou por causa do choque emocional ou por causa de uma leve coagulação cerebral-ele pode estar mais ótimo do que o primeiro. Então, num acidente tudo é emergente. Então, aqui principalmente, eu acho um absurdo e até uma omissão se tentar nesse momento, com dados clinicos, tentar diferenciar emergência e urgência... Porque, veja bem... qual é? O médico é muito onisciente, prepotente, acha que este está melhor que aquele, mas que parâmetro que ele tem? O saber técnico resolve? Por exemplo, eu participo... membro inferior, essa artéria está lesada,... digo aneurisma, evidentemente o pulso está presente, o médico palpou e falou 'o pulso está presente, não há lesão arterial'. Se esse médico tivesse feito um exame mais apurado, no minimo obteria um sopro aqui. Mas se fizer a si mesmo essa pergunta 'a presença do pulso exclui lesão arterial?', estou com certeza que a maioria dos médicos responderá que sim, mas não exclui, você pode ter uma lesão parcial (...). Não estamos capacitados, principalmente no atendimento extra-hospitalar, a estabelecer essa diferença. E quanto mais se tenta estabelecer, quanto mais se diz 'é urgência, não é emergência', mais estamos prejudicando ou contribuindo para a não assistência ou a má assistência ou, inclusive, seria até um erro, um desrespeito à vida do paciente. (...) Quem tem um conceito científico adquirido através da informação e não do conhecimento - ele foi 
informado, tem que ser assim, não tem nem reflexão-- ele [o médico] aplica aquilo que está no livro sem reflexão. (...) Ser cirurgião é ser um técnico independente de ser um médico. Ser médico, qualquer um, se basear-se nos protocolos - esses programas de emergência, os protocolos, graças a Deus, até esqueci o nome do programa que é usado pela emergência! -, pode ser médico, independente da faculdade. (...) No PS, naquele instante, não deve existir diferenciação entre emergência e urgência... Então vamos transformar em emergência e dar um pronto atendimento, porque o paciente procurou, e nós, tão-somente pela percepção, não estamos autorizados a protelar esse atendimento, ou mesmo deixar de atender.

$O$ dr. 2 condena uma distinção que, segundo ele, desemboca em uma discriminação ilegítima - e por isso, eticamente condenável - dos estados de saúde. Tal distinção leva a desconsiderar, de antemão, certos estados de saúde para valorizar outros, a partir de uma apreciação baseada na aplicação geral dos protocolos ensinados nos manuais de emergência que descrevem as etapas dos procedimentos terapêuticos a serem seguidos para os problemas de saúde repertoriados como 'emergências'. Entre outras implicações, conduz ao exame clínico superficial ${ }^{2}$ e ao descaso dos pacientes cujas queixas e/ou sintomas fogem das emergências catalogadas e descritas nesses manuais. Para o dr. 2, como para o dr. 1, só deveria existir a categoria das 'urgência(s)', todas consideradas de antemão como sérias e exigindo um atendimento rápido, até um exame apurado determinar sua gravidade.

\section{Os Sinals}

As observações de campo revelam, de fato que, por existirem duas categorias de urgências, umas consideradas 'graves' (as emergências) e as outras 'menos graves' (as urgências), as primeiras acabam sendo muito valorizadas em detrimento das segundas, que, por não serem tão urgentes, parecem se fundir no conjunto do não urgente, e, afinal, desaparecer como 'urgências'. Na rotina do pronto-socorro é como se, de um lado, estivessem as emergências urgentes, e do outro, o resto: a distinção urgência/ emergência se dissolve, para sobrar só as emergências como urgências verdadeiras, atendidas e tratadas como tal, a saber: com rapidez.

A valorização de um estado de saúde como 'grave', 'urgente' - seu alto valor mobilizador - pode ser identificada, menos graças aos discursos normativos proferidos fora de contexto ${ }^{3}$ " "isso é urgência, isso é emergência" - do que graças à observação dos comportamentos, tais como se manifestam e se dão a ver em situação. Em outros termos, ela pode ser deduzida das atitudes diferenciadas dos médicos e enfermeiros (a equipe médica), assim como do pessoal não médico do pronto-socorro (seguranças, porteiros, recepcionistas), em relação aos pacientes no momento de sua chegada e depois.

Por exemplo, a rapidez ou não do atendimento (tempo de espera), o tipo de percurso seguido pelo paciente, ${ }^{4}$ a ida ou não de um médico ou/e de enfermeiras à sala de espera (sua saída da área de atendimento) para ver ou/e buscar o paciente, o número de 
profissionais de saúde intervindo no momento de sua chegada e depois, a precipitação, o clima de tensão, o nervosismo provocado ou não pela entrada do paciente no prontosocorro, são vários indícios que, observáveis a partir da sala de espera, testemunham a forte, fraca, ou inexistente mobilização da equipe médica em relação a um paciente. São eles que indicam ao observador se um caso é considerado urgente, grave ou não pelos médicos. São eles que revelam o que é contemplado por eles como 'emergência(s)'.

Quais são, então, os sinais que - detectáveis ou não no paciente - suscitam, de maneira notável e significativa, uma forte ou fraca atenção/mobilização por parte dos profissionais da saúde que atuam no pronto-socorro?

\section{Estar InCONSCIENTE OU DeITADO}

Qualquer que seja seu problema e qualquer o meio de transporte que os levaram para o pronto-socorro, os pacientes, quando chegam sem consciência (ou desmaiam depois de sua chegada), são atendidos com bastante rapidez. O mesmo pode ser observado com os que entram no pronto-socorro deitados em uma maca: $:^{5}$ conscientes ou não, e qualquer que seja seu estado de saúde (só investigado depois por médicos), eles obtêm uma entrada direta na área de atendimento. ${ }^{6}$ Estar desmaiado ou estar deitado são dois sinais - e, especialmente, a perda de consciência - que suscitam um grau elevado de atenção por parte da equipe médica, pelo menos nos primeiros momentos da chegada do paciente. Considerados como indícios a priori, e por excelência, de uma provável emergência, são levados muito a sério e seu poder mobilizador é alto.

É só observar as reações e ações provocadas pelo desmaio de um paciente na sala de espera, para confirmar a importância dada a essa manifestação por parte do pessoal médico. Presenciei várias situações desse tipo, em que pacientes esperando quietos sua vez de ser chamados, de repente, perdiam consciência. ${ }^{7}$ Seu desmaio provocava a intervenção de seguranças, médicos e enfermeiros que os levavam imediatamente para a área de atendimento. A perda de consciência aumentava de maneira considerável o valor mobilizador desses pacientes, antes fraco ${ }^{8}$ até eles desmaiarem. Da mesma maneira, a ordem dada ao segurança da entrada para avisar a equipe médica, por meio da campainha, da chegada de alguém de maca testemunha a atenção dada aos pacientes que entram deitados.

Certos pacientes notam a importância dada à perda de consciência pelos médicos, que, cansados com a espera, fazem, brincando ou irritados, comentários como: "tenho que desmaiar para ser atendido!". Entre outros exemplos, escutei essa frase por parte de uma mulher de uns 60 anos, que estava na espera, gemendo de vez em quando, havia três horas, quando começou a conversar comigo, dizendo: "os médicos se esqueceram de mim". Tinha caído no ônibus de manhã cedo e se queixava de muita dor "por causa da costela". "Estou com medo de furar o pulmão e de infectar a carne por dentro", dizia ela. Referindo-se a uma cena presenciada de manhã no pronto-socorro, lançou em voz alta e com ironia: "vou desmaiar para ser atendida!". Contou-me que, algumas horas antes, a mulher que estava sentada ao seu lado desmaiou: "ela diz que tem dor na nuca, formigamento na mão, pressão alta. Falei para a filha dela: a sua mãe vai morrer. De repente, ela diz que tinha problema na vista, chamei um guarda: atenda essa mulher, 
você quer que ela morra? Porque dor na nuca, formigamento na mão e ela com pressão alta!". E terminando seu relato com força, voltou a gritar: "tenho que cair no chão para ser atendida!?".

Apesar de diferentes, essas duas situações altamente mobilizadoras - estar sem consciência, estar deitado - têm em comum que o paciente não anda. Não estar/ficar em pé - no momento de passar a porta de entrada do pronto-socorro ou, depois, no momento da espera - constitui um elemento de imediata visibilidade que tende a ser apreciado pelos médicos como um sinal de extrema gravidade e, por conseqüência, de emergência. Aliás, a atenção suscitada, de imediato, pelo paciente que apresenta essa característica pode baixar muito depois, quando a primeira avaliação clínica indicar que seu estado de saúde não é nem tão sério, nem tão urgente assim. Nesse caso, o paciente não volta para a sala de espera, mas continua aguardando dentro da área de atendimento.

Essa aparente equivalência - a pessoa (consciente ou não) não está de pé (não anda) $=$ seu caso é possivelmente grave - não existe só para os profissionais da saúde. O sinal 'estar deitado' chama atenção e alerta os profissionais não médicos do prontosocorro, os atendentes das centrais de chamadas, os motoristas de veículos de socorro, os transeuntes. Basta considerar, por exemplo, o grande número de chamadas recebidas pela Central de Ambulâncias que diz respeito a "uma pessoa deitada na rua". Geralmente, os solicitantes desconhecem a pessoa e nem se aproximaram dela antes de telefonar. ${ }^{9}$ Mas o simples fato de ela estar no chão os preocupa a ponto de eles ligarem para o 192 ou o 193. Em relação ao sinal 'estar deitado/não andar', profissionais da saúde e leigos compartilham a mesma apreciação inquieta: para todos, é um sinal de gravidade.

\section{Andar, Ficar em Pé, Falar}

Para os profissionais da saúde que atuam no pronto-socorro, não só vale a equivalência anterior, mas também o seu contrário. A espera a qual estão submetidos os pacientes que chegam e ficam em pé, e os percursos por eles seguidos, revelam a existência da equivalência oposta, a saber: a pessoa fica em pé (anda) = seu caso certamente não está sério (grave). No pronto-socorro, 'andar' e 'falar' são sinais que não favorecem um atendimento rápido e que são lidos como indícios de um estado/ situação de saúde que 'pode esperar'.

Os pacientes que apresentam essas características ${ }^{10}$ são encaminhados primeiro para a recepção, pelo segurança da entrada; depois, para a sala de espera, pela recepcionista que preencheu sua ficha. O que significa que os profissionais com quem os pacientes estabelecem os primeiros contatos - até conseguirem a consulta médica são dois tipos de agentes sem nenhuma formação médica: eles apreciam o estado de saúde como 'podendo esperar'; são os primeiros a lerem os sinais - 'está andando', 'está falando' - como indícios de um estado não preocupante.

Se os médicos do pronto-socorro não compartilhassem da mesma leitura, é de se duvidar que deixariam a primeira avaliação dos pacientes que andam e falam na mão de não especialistas que julgam por meio de um olhar superficial e rápido ${ }^{11}$ e de algumas perguntas. Se não fosse o caso, há de se pensar que, pelo menos no momento da primeira triagem (por exemplo, no momento do preenchimento da ficha), encontraria-se 
um profissional mais capacitado, do ponto de vista médico, para avaliar se o paciente pode ou não aguardar a consulta, e também para determinar, em termos de espera, a ordem das prioridades entre os pacientes que andam e falam.

Um efeito problemático da segunda equivalência é que ela desemboca no descaso da maioria dos pacientes e, especialmente, dos que são chamados 'casos clínicos'. De maneira geral, eles não chamam a atenção e constata-se que seu valor mobilizador é baixo. Contudo, da mesma maneira que nem toda pessoa desmaiada ou deitada está em um estado necessariamente preocupante, nem toda pessoa que fica em pé está necessariamente em um estado bom ou, pelo menos, razoável. A diferença, entretanto, é que, no primeiro caso, os pacientes se beneficiam de uma suspeita de gravidade que se traduz por uma primeira avaliação clínica que visa justamente a conferir a seriedade (urgência) do estado e a necessidade ou não de um diagnóstico mais apurado; enquanto, no segundo caso, os pacientes, por não se beneficiarem dessa suspeita, aguardam, até por muito tempo, o momento de serem examinados por um especialista médico e de serem medicados.

Ora, durante a espera, o problema/estado de saúde do paciente pode piorar a ponto de virar uma urgência/emergência. E se não sofre conseqüências tão dramáticas, com freqüência vivencia um sofrimento e uma angústia provocados ou aumentados pela própria demora do atendimento. Nesse caso, a situação de espera não coloca em risco sua vida, mas não deixa de levantar a questão de saber até que ponto se pode, eticamente falando, infligir esse sofrimento (físico e moral) aos pacientes que ficam em pé. E não somente a eles, mas também a quem os acompanha. Penso, particularmente aí, nas mães e pais que, já bastante preocupados no momento da chegada no prontosocorro, ficam esperando, agoniados, um atendimento para sua criança pequena. $\mathrm{Vi}$ acompanhantes de crianças como também de adultos e idosos tão angustiados pela espera que, não agüentando mais, ${ }^{12}$ acabavam deixando o pronto-socorro do Hospital das Clínicas com o doente para ir à procura de um atendimento em outro lugar.

O emprego do verbo 'infligir' não é fortuito. Observei freqüentemente que a espera dos pacientes 'de pé' não se explicava pela atividade dos profissionais de saúde, ocupados com casos que seriam mais urgentes e, por isso, prioritários. Muitas vezes, as salas de espera estavam cheias, enquanto vários médicos, residentes e enfermeiras se encontravam desocupados nas áreas de atendimento, e especialmente na sala de conforto, destinada ao descanso desses profissionais. De uma maneira geral, o contraste era forte entre as salas de espera, lotadas, movimentadas e barulhentas, e as calmas áreas de atendimento atravessadas, com tranqüilidade, pelo branco das blusas e calças. Era um pouco a paz versus o tumulto.

Entre numerosos exemplos de falta de consideração pelos casos clínicos e de seus efeitos negativos nos pacientes e acompanhantes (em termos de espera, risco e sofrimento), há o caso de uma mulher jovem (uns 20 anos) que fomos buscar de ambulância, uma manhã, na favela Argolo Ferrão, de Marília. Segundo o atendente da Central do 192, que se comunicou por rádio com o motorista, tratava-se "de um menino com febre". "O que foi passado para nós é isso", acrescentou ele, e, com essa informação, fomos à favela. 
Chegando lá, o motorista teve de parar, pois a rua estava com buracos tão grandes que não dava para ir até a casa da solicitante. Foi ela quem veio a pé até a ambulância, com seu neném nos braços, enrolado em um pano. Quando chegou na altura da ambulância, deu para ver que estava chorando e muito nervosa. Uma mulher trabalhando em uma lanchonete ao lado, comentou conosco: "o neném está virando os olhos". A mãe repetiu a mesma coisa, e subiu atrás da ambulância com a criança. No momento de dar a partida, o motorista comentou para mim: "Do que ela disse, parece que convulsou a filha dela".

Estávamos andando na estrada quando gritou a mulher atrás pedindo para o motorista parar porque a criança "tinha virado os olhos de novo". Ele parou imediatamente para ver o neném e tranqüilizar a mãe, muito assustada, e voltou para a frente da ambulância falando: "é nesses momentos que faz falta uma ambulância boa". Deu a partida, mas, dessa vez, aumentou bastante a velocidade. Essa aceleração associada ao uso repentino da sirena denotavam que, para ele, o caso da criança tinha virado urgente. ${ }^{13}$ Aliás, ele também abriu a janelinha da separação existindo entre a parte traseira e dianteira da ambulância, para poder jogar uma olhada atrás, de vez em quando, "para ver se está tudo bem". Comentou comigo que "não dá para estar ao mesmo tempo no volante e atrás", e também me informou que "no caso de uma convulsão, não tem nada para fazer"; é "só dar uma inalação para evitar a asfixia".

Uma vez no pronto-socorro, o motorista ajudou a mulher com o neném a descer da ambulância. Foi com ela até a recepção, deixou-a na fila pedindo-lhe para "esperar um pouquinho" que ele já estava de volta, e foi direto para a área de atendimento do pronto-socorro infantil à procura de um médico que pudesse examinar logo a criança. $O$ comportamento do motorista indicava o quanto achava sério o caso do neném: ele ia tentar acelerar seu atendimento chamando a atenção de um médico. Ao primeiro que encontrou pediu com bastante precaução (isto é, sem parecer estar lhe ditando o que devia fazer) para sair na sala de espera para ver um nenê que "parece estar com convulsão". Este respondeu de maneira firme que não era pediatra. O motorista insistiu, mas o médico também, repetindo sua primeira resposta: não era pediatra e, então, esse caso não era dele.

Um outro médico passava no corredor, e o motorista o parou e voltou a expressar o mesmo pedido. Este respondeu que estava saindo, pois era sua hora de almoço. $\mathrm{O}$ motorista insistiu, e o médico repetiu que era sua hora de almoço. Mais firme do que a primeira vez, o motorista continuou persistindo, dizendo que era só ele dar uma olhada na criança. Aí o médico perguntou, num tom mais afirmativo do que interrogativo, "aconteceu ontem?", e o motorista respondeu que não, que a mãe tinha dito que tinha começado de manhã. Ao final dessa conversa tensa, o motorista obteve a saída na sala de espera do médico, que, pressionado, manifestava descontentamento e pressa.

Uma vez lá, na fila onde se encontrava a mulher, que continuava chorando, o médico jogou um olhar breve na criança (enrolada no pano e com os olhos abertos) e fez, em seguida, várias perguntas curtas para a mãe, mas sem lhe dar o tempo de responder: "desde quando?", "foi hoje?", "foi ontem?", "desde quando?", mas sem lhe dar o tempo de responder, acabando ele mesmo respondendo por um: "foi ontem", afirmativo. Sua única preocupação parecia ser a de saber quando tinha acontecido o problema, 
e a impressão que dava era que queria absolutamente que tivesse ocorrido 'ontem'. No momento, eu não compreendia por que insistia tanto em impor esse 'ontem' ${ }^{14}$ Também não entendia por que não se interessava pelo problema da criança, não a olhava e nem a tocava para, pelo menos, mexer com o pano que a recobria toda. Mas o que percebia é que o médico ignorava o neném e queria que seu problema fosse do dia anterior.

Quando conseguiu um espaço para falar, a mãe disse que não tinha acontecido ontem, mas "essa manhã". Em resposta, o médico voltou a lhe fazer exatamente as mesmas perguntas como se, ficando surdo, não tivesse escutado nada e concluiu de novo: "foi ontem". A mãe repetiu que não, que o problema tinha acontecido de manhã e, dessa vez, acrescentou: "ela vomitou, saiu alguma coisa pela boca e os olhos viraram, e recomeçou agora". Neste momento, o médico olhou para o motorista e falou que não era convulsão: "a mãe se assusta porque não sabe"; este foi o último comentário que fez antes de ir embora e desaparecer na área de atendimento infantil.

Como não era conveniente insistir mais - dentro de uma relação altamente hierarquizada na qual o interlocutor era médico enquanto ele era apenas um simples chofer de ambulâncias -, o motorista renunciou. Tocou o ombro da mulher de maneira amigável e disse para ela continuar na fila, que iria ser atendida. Fomos embora, deixando-a calada, esperando sua vez, e atravessamos, silenciosos, a sala de espera do pronto-socorro: eu, atormentada por causa da cena que tinha acabado de presenciar e com sensação de muita impotência. Uma vez na ambulância, o motorista, revoltado, falou para mim: "ele disse que a mãe está assustada porque não conhece, mas como que ele sabe se nem examinou? Ele nem olhou para o nenê! Se fosse sua filha, acha que ele teria toda essa tranqüilidade?". E acrescentou um pouco depois: "se eu insistir demais, eles vão se queixar para a Central que eu invado seu campo".

Um certo descaso pelos casos clínicos pode ser observado também na ausência freqüente de um médico nas salas de triagem clínica infantil e, sobretudo, adulta, do pronto-socorro. Nesses lugares é atendida a maioria dos pacientes classificados como 'caso clínico' e considerados como 'podendo esperar' pelos seguranças, porteiros e recepcionistas. Na sala de triagem, eles passam por um primeiro exame feito por um médico, destinado a investigar e identificar seu problema. É por essa consulta que espera a maioria das pessoas, e é a partir dela que se vai desenhar, para cada um, o próximo trecho do percurso a seguir.

Certos pacientes, cujo caso é resolvido no momento da consulta, são mandados de volta para a casa com uma receita na mão. Outros continuam esperando porque o médico pediu exames a serem feitos no próprio Hospital das Clínicas: no que diz respeito por exemplo, ao raio-X, o paciente desce ao andar inferior onde aguarda sua vez. Outros ainda voltam à sala de espera onde ficam aguardando uma consulta na área de atendimento.

Destinada a desafogar o pronto-socorro, a triagem clínica tem também a função declarada de avaliar o nível de gravidade dos problemas apresentados pelos pacientes, no intuito de determinar o grau de urgência, mais ou menos grande, ou até nulo, do atendimento a lhes ser dado, isto é, sua inscrição na ordem das prioridades. Ora, muitas vezes, as salas de triagem estão vazias e por muito tempo (de uma a várias horas). As fichas dos pacientes adultos vão se acumulando na caixa que se encontra do lado da 
porta da sala de triagem adulto, depositadas no decorrer do tempo pelas recepcionistas. De vez em quando, o médico que atua na triagem sai da área de atendimento adulto para pegar o pacote de fichas, volta para a área de atendimento onde desaparece durante um tempo, geralmente longo, reaparece na sala de espera, mas não entra na sala de triagem, desaparece de novo, até o momento que começa atuar na triagem chamando vários pacientes em seguida. Depois de algum tempo, sai novamente, volta para a área de atendimento onde desaparece por um bom tempo e assim por diante.

A ausência de um médico atuando de maneira permanente na triagem testemunha o valor mobilizador muito baixo dos pacientes a serem examinados por ele. Dessa situação, só se pode deduzir que nenhum dos ditos 'casos clínicos' está a priori considerado como possivelmente urgente. O que leva a concluir, por fim, que "quem pode esperar" na apreciação primeira dos seguranças, dos porteiros e na avaliação das recepcionistas que preenchem as fichas sumárias transmitidas ao médico da triagem, também 'pode esperar' para os médicos. Pode esperar e, muitas vezes, espera mesmo: geralmente até receber um atendimento, às vezes até desistir e, em alguns casos, até morrer.

\section{Estar com um Problema Repentino}

De maneira geral, constata-se também que é dada mais atenção ao paciente quando seu problema acabou de surgir. As perguntas "desde quando está com essa dor?", "desde quando está assim?", são entre as primeiras feitas aos pacientes pelas recepcionistas, no momento de preencher a ficha; pelos médicos e enfermeiros, quando atendem, e pelo pessoal das centrais de urgência/emergência, no telefone. Quando a pessoa responde "desde ontem à noite, há uma semana, um mês", muitas vezes, escuta o seguinte comentário: "mas por que não veio consultar antes?". E só por ter respondido que seu problema não é de agora, sai da categoria das possiveis urgências/emergências.

Dodier e Camus (1997a: 113) chegam à mesma constatação no que diz respeito à França quando fazem observar que mais os usuários do pronto-socorro argumentam com as recepcionistas que sua dor existe desde tempo, "menos chance têm de serem atendidos". ${ }^{15}$

A questão do tempo não é, então, nada acessória: pois mais um paciente sofre de um problema antigo, mais será considerado como apto a esperar, conforme o seguinte raciocínio: já que o paciente esperou até agora, pode esperar um pouco mais. E mais: já que o problema esperou até agora, não é urgente (pois se fosse já estaria morto), então, não tem urgência em tratá-lo. Este raciocínio talvez seja esquisito para um observador exterior, na medida em que, segundo o raciocínio exatamente oposto, também se poderia considerar que o problema do paciente acabou se tornando urgente justamente por ele ter deixado passar tempo demais até consultar no pronto-socorro. Da mesma maneira, se poderia pensar que um sintoma (por exemplo, uma dor, que representa um caso bastante comum) que 'desde ontem', 'uma semana', 'um mês' não desapareceu, é o sinal possível de um problema sério que poderia ser encarado como tal, pelo menos de imediato, pelos profissionais da saúde que atuam no pronto-socorro. Mas para os médicos como, aliás, para as recepcionistas e os atendentes das centrais, é o primeiro raciocínio que prevalece. 
No que diz respeito às representações da urgência/emergência por parte dos médicos, esse dado vem, então, afinar as considerações anteriores: mais o problema (o sintoma) do paciente é novo, mais tende a ser considerado como o sinal de um mal possivelmente urgente. Aliás, 'novo' não é bem a palavra adequada. Para ser considerado como urgente e ser examinado com rapidez, o problema deve ter acabado de acontecer ou de se manifestar. Em outros termos: o que tende a ser considerado como possivelmente urgente é o que acabou de emergir. A partir daí, não é de estranhar que todo problema de saúde que apresenta um caráter crônico caia a priori fora do urgente, como ilustra de maneira exemplar esse comentário de um residente do pronto-socorro: "um toque [de campainha], não é uma urgência. Pode ser até um problema crônico, mas, enfim, mesmo assim precisa de uma maca".

Essa representação do que é urgente explica um outro fato importante, que será desenvolvido a seguir, a saber: a supervalorização, por parte dos profissionais da saúde do pronto-socorro, dos estados traumáticos como urgências e, sobretudo, como emergências. A superestimação dos estados traumáticos em relação aos casos clínicos encontra sua raiz na interpretação muito literal, ${ }^{16}$ do que é uma emergência, isto é, alguma coisa que acabou de surgir, de acontecer. O problema de saúde que apresenta essa característica tende a ser, a priori, considerado e tratado como uma emergência, o que é o caso, por excelência, dos estados traumáticos decorrentes de acidentes ou de choques que acabaram de ocorrer.

A desconsideração pelos problemas/sintomas antigos é notável nas numerosas histórias de pacientes 'chatos' contadas por médicos e residentes de medicina. Seu conteúdo é variável, mas, no fundo, quase sempre relatam a mesma história: a de pessoas que vieram consultar no pronto-socorro em um momento considerado inoportuno para um problema que não era novo, pois, como os próprios contadores se perguntam: "por que procurar o pronto-socorro agora?" - isto é, segundo as histórias narradas, no meio da noite, na noite do ano novo, na véspera do natal, perturbando o sono ou as comemorações dos que estão de plantão - "para um problema que, por ter esperado até esse momento, podia esperar ainda mais?".

Nos relatos, até parece que esses pacientes se dirigem ao pronto-socorro no meio da noite só para incomodar. Ilustração exemplar dessas histórias é a contada por um médico atuando na triagem clínica infantil. Ela diz respeito a um pai que levou sua filha para o pronto-socorro "na noite do Reveillon, às 23:54", no momento em que todos os médicos e residentes de plantão tinham acabado de se reunir para festejar a passagem do ano. "A menina estava com dor de ouvido desde três dias e é nessa hora, na meia-noite da passagem do ano, que traz ela!", exclamou. Contou ter perguntado para o homem porque vinha naquele momento, já que a menina estava com dor há três dias, ao que ele respondeu: "porque a minha filha está com dor". Acrescentou também que quando deu a receita médica para o pai, este perguntou: "onde que vou encontrar uma farmácia aberta nesta hora?", e resolveu ir buscar os remédios na manhã seguinte. "Então, por que vir nesse momento, encher o saco da gente, se é para comprar os remédios no dia seguinte?", concluiu o médico, indignado, com uma lógica implacável.

As histórias contadas para ilustrar as 'verdadeiras emergências' são bem diferentes: dizem sempre respeito a acidentes de carro, de avião, de trem e, para a chegada das vítimas 
neles envolvidas não há momentos inoportunos, nem no meio da noite. Ao contrário, o fato de elas chegarem no meio da noite parece aumentar ainda o caráter espetacular dessas emergências e a satisfação de quem estava de plantão para atendê-las.

\section{Estar con Dor}

Uma relativa indiferença à dor pode ser observada por parte do conjunto do pessoal médico e não médico que atua no pronto-socorro. Uma exceção deve ser feita em relação aos seguranças, que, muitas vezes, vi entrar na área de atendimento no intuito de chamar a atenção de um médico para um paciente que estava se queixando de sofrer muito ou manifestando muita dor. Importa dizer que se tratava, quase sempre, de pacientes mulheres. Os seguranças se mostravam bastante sensibilizados pelo sofrimento e lágrimas das mulheres na sala de espera, para as quais, muitas vezes, tentavam apressar a consulta, às vezes com sucesso. Um deles também sempre se mobilizava para tentar obter dos médicos o atendimento rápido dos pacientes com cólicas renais, independente do sexo. Por ter experimentado, justificava-se, dizendo que a dor é terrível: "uma dor que não dá para agüentar".

Exceção feita ao caso um pouco especial dos seguranças, ${ }^{17}$ constatei, de maneira geral, que o sofrimento físico não tem incidência sobre o tempo de espera para um atendimento. A dor não é lida pelos médicos como um sinal de urgência ou de emergência, qualquer que seja o comportamento do paciente: quer manifeste sua dor (gemendo, contorcendo-se, gritando, chorando), quer fique quieto.

Do ponto de vista do discurso, as falas desses profissionais deixariam até pensar que ficam mais preocupados com um paciente que não expressa nada - esse que "fica calado em seu canto" - do que com os que expressam, de maneira visível e sonora, seu sofrimento. Pois, segundo eles, um paciente "barulhento" mostra, pela própria extroversão de seu sofrimento, que não está tão mal assim: se ficasse ruim mesmo, não teria tanta energia. Visto sob esse ângulo, gemer, gritar, queixar-se, protestar, são interpretados como sinais de saúde ou, melhor, de vida. Mas, como de um outro lado, a observação revela que ficar quieto também não aumenta o valor mobilizador do paciente, mas até tende a diminuir suas chances de conseguir mais atenção no decorrer da espera, ${ }^{18}$ manifestar a dor ou ficar quieto dá no mesmo.

Para muitos médicos e enfermeiros, o sofrimento tanto físico quanto moral - sua vivência e expressão - diz respeito à esfera psicológica e, por isso, é desacreditado ("é psicológico"), objeto de desconfiança ("o paciente finge") e de desprezo ("quem grita, está ótimo"). Uma ilustração dessa constatação pode ser encontrada na conversa, bastante esclarecedora, de um médico aconselhando um porteiro do pronto-socorro cuja função é, entre outras, barrar a entrada indesejada de pacientes ou de acompanhantes na área de atendimento. O médico explicou para ele que devia ser simpático com os pacientes que esperam, pois "quem vem aqui, a maioria não é urgência", "não tem nada", " $50 \%$ é psicológico". O porteiro tinha de se mostrar simpático, sobretudo, com "a pessoa que se queixa de dor forte", pois, se ficar "brusco com ela, vai se sentir pior e se queixar de uma dor maior", enquanto "se conversar com ela, a dor passa e ela vai embora tranqüilamente". Como prova, apontou para uma moça que estava chegan- 
do no pronto-socorro, muito agitada, gritando e tremendo, e falou: "você vê o que estou dizendo, é psicológico".

A colocação anterior pode ser, aliás, estendida a todos os sintomas e problemas que apresentam uma dimensão psicológica explícita, ${ }^{19} \mathrm{e}$ mais ainda quando se manifestam em mulheres, aparentemente tidas, por numerosos médicos, como grandes atrizes. As risadas, brincadeiras e comentários cúmplices (muitas vezes de conotação sexual) trocados entre médicos (e residentes) a propósito das mulheres que chegam em estado de grande agitação testemunham seu descaso, e até seu desprezo, por essas pacientes exageradas que "não têm nada físico".

Bastante significativas são as várias denominações que lhes são dadas, tais como "peripaque", "piti", "SVC" (Síndrome da Vagina Carente), "SPA" (Síndrome do Pênis Ausente). O problema dessas mulheres "é a cabeça", e, por isso, não é levado a sério em termos de gravidade e de urgência, pois o corpo não está explicitamente comprometido, nem as "funções vitais".

Entre as dores, uma é figura de exceção, pois é geralmente levada muito a sério pelos médicos, sobretudo se é recente: a 'dor no peito'. Ela confere ao paciente um valor mobilizador alto que se traduz por um atendimento rápido, pois pode ser o sinal de um enfarte que, entre os ditos 'casos clínicos', é considerado como a emergência por excelência. Nos exemplos de emergências que dão os médicos, o enfarte é o único problema de saúde não decorrente de um trauma físico, sistematicamente citado ao lado dos acidentes. Assim, é considerado também pelos seguranças e atendentes de centrais. Segundo bombeiros que atuam na central do 193, o enfarte é o único 'caso clínico' que resgatam sistematicamente, como o fazem com os problemas resultantes de acidentes, pois, como estes, é uma emergência.

Certos pacientes sabem do valor dado à 'dor no peito' e a assinalam quando querem a vinda do Resgate ou de uma ambulância. É comum os solicitantes se referirem a esse sintoma no telefone, e os motoristas do 192 descobrirem, uma vez no lugar, que a pessoa a ser atendida nunca sentiu essa dor, mas está sofrendo de outra coisa, por exemplo, de coma alcoólico, para o qual se teme não conseguir a assistência da ajuda móvel de urgência. A mesma observação pode ser feita no pronto-socorro. A importância dada pela equipe médica à dor no peito é facilmente perceptível e certos pacientes se queixam desse sintoma no intuito de apressar o atendimento. A cena seguinte exemplifica a atenção explícita dada a essa dor pelos médicos.

Uma tarde, a médica responsável pela triagem clínica veio à sala de espera com um maço de fichas na mão. Chamou um paciente que não estava, e depois, em discurso aberto às pessoas que aguardavam, disse que o movimento estava sobrecarregado, assim sendo os "casos mais graves" deveriam ter a preferência. Posto isso, começou, a partir das fichas, a chamar um paciente de cada vez, fazendo-o levantar e em seguida sentar novamente. À primeira perguntou se sentia dores fortes, e esta prontamente respondeu que sim. A médica perguntou, então, se era possível que esperasse mais um pouco. Em seguida, a mulher sentou-se com uma cara de pobre infeliz, e a médica continuou sua volta: "quem tiver alguma coisa mais grave..., você está com dor no peito ou na garganta?". Ao final de sua pesquisa, não tendo aparentemente encontrado 
ninguém que se encaixasse na categoria 'caso grave', perguntou a todos : "alguém está com dor no peito ou alguma coisa assim?".

Levantou-se uma mulher, cerca de 40 anos, dizendo sentir dor no peito. A médica pôs-se a perguntar-lhe por que, então, ela não tinha posto tal sintoma na sua ficha. Como a atitude e a resposta da mulher não eram muito convincentes, a médica, achando que ela tinha mentido, mandou um enfermeiro, que passava por lá, avisar "um médico" sobre suas dores no peito e voltou para a sala de triagem, onde se fechou.

O resultado da interação foi, então, que a mulher continuou aguardando o atendimento, mas, dessa vez, muito descontente: "coisa de governo é coisa de governo. Eu vou chamar o Ratinho. Ele mete a boca no trombone. Pelo menos melhora para outras pessoas. Nem que seja a última coisa que eu faça na minha vida!", comentou para todos. Ela tinha sido encaminhada de Adamantina para que fosse realizado um enxerto em sua perna, pois tinha sido mordida por um cachorro.

\section{Estar com Trauma Físico}

Os estados de saúde que têm e, de longe, o maior valor mobilizador são os estados traumáticos (ou possivelmente traumáticos) que apresentam sinais visíveis e impressionantes, tais como sangue, perda de consciência, feridas e fraturas visíveis. Resultam de acidentes diversos, tais como os de trânsito, atropelamentos, quedas, acidentes do trabalho, entre os mais comuns.

Em vitimas de acidentes, suspeita-se a existência de possiveis traumas, isto é, de problemas causados de maneira súbita por um agente físico e especialmente por um choque violento. Para os médicos, importa identificar e avaliar rapidamente do que sofrem. Por isso, essas vítimas são atendidas com pressa à medida que apresentam um ou vários dos sinais visíveis anteriormente citados, e, sobretudo, a perda de consciência. De maneira geral, as vitimas de acidentes tendem a ser a priori consideradas e tratadas como possíveis urgências ou emergências. Elas se beneficiam de uma suspeita de gravidade que não suscitam os outros pacientes, especialmente, os ditos 'casos clínicos' (com as exceções já assinaladas), pois se estes são considerados como possivelmente não graves, os primeiros são encarados como provavelmente sérios e urgentes.

Chega-se, então, à seguinte compreensão: entre os problemas de saúde, os que têm maior poder mobilizador, os mais valorizados como urgências/emergências, são os decorrentes de choques físicos repentinos. E, entre eles, ainda existe uma escala entre os mais e menos mobilizadores. Os mais valorizados são os que ocorrem em conseqüência de acidentes com suspeita de politraumatismo, como é o caso dos acidentes que acontecem na estrada ou que envolvem veículos de transporte. Emergências por excelência, esses estados (possivelmente) traumáticos também chamados pelos médicos de "emergências cirúrgicas", são, de longe, os mais espetaculares. São eles que os profissionais de saúde sempre citam quando querem definir ou ilustrar o que é uma emergência, tal como esse residente de medicina que relatou bastante animado: "ontem à noite você perdeu uma urgência, uma verdadeira essa, uma emergência! O piloto de um avião que caiu em uma casa de Marília!'. São esses casos que os médicos, que afirmam gostar de trabalhar na urgência/emergência, também dizem preferir atender. São eles que "fa- 
zem subir a adrenalina" ${ }^{20} \mathrm{e}$ cuja chegada ao pronto-socorro é assinala pelo segurança à equipe médica por dois toques de campainha.

A maioria das vezes, esses casos são levados pelos bombeiros, o que também tem um impacto na mobilização e na rapidez do atendimento, pois casos semelhantes que chegam por meios próprios (de carro particular, de ônibus) não são atendidos com tanta rapidez. Deu para observar vários casos, de homens, sobretudo, vindo se consultar por meios próprios por causa de acidentes ${ }^{21}$ que, depois de terem passado em pé pela porta do pronto-socorro, sem sinais aparentes ou sem sinais aparentes impressionantes ${ }^{22}$ foram preencher sua ficha. Eles esperaram, às vezes, por muito tempo, sem ver um médico até serem atendidos, sem receber um exame clínico nem superficial na chega$\mathrm{da}$, isto é, sem que fosse avaliada a gravidade das lesões das quais podiam estar padecendo, mesmo que conscientes (por exemplo, hemorragia interna, lesão arterial parcial etc.). Em comparação, pacientes conscientes, vítimas de acidentes, que chegavam na viatura do Resgate, eram levadas diretamente para a área de atendimento.

Além da questão do transporte, tem-se que ver também que os primeiros pacientes passavam pela porta do pronto-socorro andando e conscientes, enquanto que os segundos, mesmo que conscientes, entravam geralmente deitados em maca, o que nos remete ao que já fora dito sobre a incidência desta situação no atendimento: quem passa em pé pela porta do pronto-socorro, e não só os acidentados, aguarda mais (e bem mais) o primeiro atendimento do que quem entra deitado, desmaiado ou não, em um estado apreciado pelos bombeiros ou pelos motoristas de ambulância como grave ou não.

Ilustração da mobilização menor suscitada pelos pacientes que, vítimas de acidentes, não chegam de bombeiros, entram andando e não apresentam os sinais visíveis e impressionantes anteriormente citados, é o caso de uma família de aparência muito humilde que o motorista de um carro particular deixou, num final de tarde, na porta do pronto-socorro meio vazio.

O pai e a mãe entraram com os dois filhos pequenos, uma menina de uns 2 anos e um menino de uns 7 anos. A criança maior mancava e segurava, chorando e gemendo, seu braço aparentemente quebrado. O pai pediu para a recepcionista o atendimento imediato da criança. Em resposta, ela pediu para ele preencher a ficha e esperar. Ele insistiu, dizendo que seu filho estava com o braço quebrado e com muita dor, mas foi sem sucesso, e a família toda foi sentar-se à sala de espera do pronto-socorro infantil, vazia. O menino continuava segurando seu braço, chorando e gemendo baixinho, enquanto a mãe, silenciosa, manifestava sinais de preocupação extrema.

Depois de algum tempo, o pai levantou e foi para a recepção onde voltou a pedir um pronto-atendimento e recebeu a mesma resposta: tinha de esperar sua vez. Voltou a sentar-se, visivelmente descontente. Durante esse tempo todo, nenhum médico (ou residente) saindo da área de atendimento infantil ou adulta parou para dar uma olhada na criança (também não tinha nenhum médico atuando na sala de triagem clínica infantil).

Ao fim, cerca de quinze minutos depois, o pai levantou-se novamente, dessa vez com a família toda, e eles se encaminharam para a saída do pronto-socorro. Quando passaram na frente das recepcionistas, houve uma breve troca de palavras que não escutei, e continuaram atravessando a sala de espera adulta em silêncio, o menino ainda chorando baixinho e segurando seu braço. Passando a porta do pronto-socorro, a mãe 
disse para o segurança que ficou quieto: "não tem médico. É possivel uma coisa dessa?". E foram embora, descendo a pé a rampa de acesso ao pronto-socorro.

Vendo isso, fui falar imediatamente com as recepcionistas para saber o que tinha acabado de acontecer com essa família. A mulher que cuidou do caso, ainda nervosa, falou com bastante irritação que "não quiseram esperar", criticou em seguida a atitude errada deles, ressaltando a impaciência e a falta de compreensão de que "não tem só eles". "O ortopedista ${ }^{23}$ está ocupado. É sempre assim: chegam e já querem ser atendidos!", concluiu a recepcionista, generalizando seu comentário a todos os pacientes que procuram o pronto-socorro. ${ }^{24}$

Afinal, se as vítimas de acidentes (e, especialmente, de acidentes acontecidos na estrada, envolvendo ou não meios de transporte) aparecem tidas como as emergências por excelência, é porque muitas vezes juntam todos os grandes sinais que têm um alto poder mobilizador dentro das representações da urgência/ emergência: estar desmaiado; estar deitado (consciente ou não); chegar na viatura do Resgate; estar com um problema que acabou de surgir e que engaja explicitamente o físico por decorrer de choques com coisas materiais. A essas caracteristicas, há de acrescentar outra importante: a presença de sinais visiveis e impressionantes no paciente, tais como sangue, feridas e fraturas expostas etc. E não só isso: o caráter também muito visível e impressionante da situação que deu origem aos (possíveis) problemas dos pacientes, isto é, o próprio acidente, cujo aspecto espetacular parece aumentar ainda o caráter possivelmente emergente do estado de saúde de quem está envolvido nele. Nos exemplos de emergências que me davam, certos médicos comentavam com ênfase o próprio acidente, apesar de não o terem visto, pois não vão buscar as vitimas.

Parece, então, que as urgências e, mais ainda, as emergências são representadas e identificadas, na base das características gerais apresentadas pelos problemas de saúde que decorrem de choques físicos e pelo tipo de situação que provocam os acidentes. É como se, na prática, existisse e se concretizasse a seguinte equivalência: emergência = casos traumáticos, isto é, casos que levam à suspeita da necessidade de uma intervenção cirúrgica rápida. A identificação da emergência com a necessidade de uma operação imediata fica bem resumida e explicitada em uma frase ouvida várias vezes da boca de profissionais da saúde: "é emergência porque vai para a cirurgia".

Ora, os estados de saúde da imensa maioria das pessoas que vão para o prontosocorro não apresentam os caracteres de uma emergência pensada a partir dos (possíveis) estados traumáticos oriundos de acidentes. Não sendo necessariamente menos graves do que os dos acidentados, seus problemas apresentam sinais geralmente mais discretos: suas manifestações físicas são menos visíveis e espetaculares; suas causas menos impressionantes e brutais. Por se afastarem dos sinais nobilizadores que fazem sentido dentro das representações biomédicas da urgência/emergência, esses casos não são valorizados como urgentes ou emergentes; tendem a se fundir na vasta categoria dos problemas que 'podem esperar': categoria ampla em que, afinal, revela-se difícil presenciar e identificar, em contexto, aquilo que pode esperar menos daquilo que pode esperar mais. 


\section{Notas}

1 Precisa assinalar de antemão que essa familiaridade não é compartilhada por outros profissionais não médicos da rede de atendimento às urgências e emergências e, menos ainda, pelos usuários (pacientes e acompanhantes), que não só não se referem espontaneamente a essa distinção, mas também não estão acostumados com a utilização do termo 'emergência(s)'.

2 Quando existe, pois o diagnóstico, no pronto-socorro, muitas vezes com base, segundo o dr. 2, nos resultados obtidos a partir dos instrumentos da tecnologia médica (raio-X, ultra-som etc.) e não sobre o exame clínico, inexistente.

3 Expressão de uma construção que não informa sobre o que acontece, de fato, no nível das práticas, isto é, em situação.

4 Ver Capítulo 3.

5 O que é geralmente o caso, quando chegam de bombeiros.

6 A mesma observação pode ser feita em relação aos pacientes que entram sentados no pronto-socorro, em uma cadeira de rodas que lhes dá o segurança da entrada. Mas ela é menos sistemática, pois, aí, são outros sinais levados em conta (como o estado aparente do paciente, o caso de um retorno ou não) que fazem com que os pacientes esperem ou sejam objetos de uma atenção imediata. Se, de uma maneira geral, entrarem sentados, tende a acelerar o processo que leva a um primeiro atendimento, entrar deitado garante mais sua rapidez.

7 Foi, por exemplo, o caso dramático de uma mulher com uns 55 anos, que estava esperando sua vez há muito tempo, sentada e quieta, na sala de espera. Quando começou a desmaiar, um segurança se precipitou para segurá-la e impedir sua queda no chão. Levada imediatamente para a área de atendimento médico, foi atendida na hora e morreu pouco tempo depois. Estava com edema pulmonar.

8 Como é o caso de todos os pacientes que esperam, durante muito tempo, sua vez de serem atendidos.

9 Os solicitantes geralmente alegam medo, e os atendentes da Central têm grande dificuldade em conseguir que eles se aproximem da pessoa a socorrer para lhes dar maiores informações sobre seu estado.

10 Exceção feita aos que se queixam - na entrada ou no momento de preencher sua ficha - de certos sintomas levados a sério por serem considerados sinais de uma possível emergência: entre os mais comuns, a "dor no peito", a "falta de ar" e as "dores do parto", para reproduzir aqui as expressões usadas pelos pacientes. Os que se queixam desses problemas geralmente não esperam tanto quanto os outros. Retomaremos mais detalhadamente essa questão.

11 Através da grade no caso das recepcionistas que preenchem as fichas.

12 A angústia está aqui ligada à impressão, por parte do acompanhante, que o paciente, já muito mal, está piorando, isto é, que vai acabar morrendo na espera. Também 
está relacionada ao sofrimento, não aliviado, do doente cujas manifestações acabam se tornando intoleráveis para quem o acompanha.

13 Em todo tempo que acompanhei os motoristas, raros foram os momentos em que usaram a sirene e andaram com velocidade.

14 Entendi melhor depois, quando, no decorrer do trabalho de campo, dei-me conta de que, dentro de suas representações da urgência e da emergência, os médicos tendem a dar mais importância a um problema (ou sintoma) quando acabou de acontecer ou de manifestar-se. Essa constatação será examinada a seguir.

15 Aos usuários que adiantam que seu caso é grave ("Morro de dor desde três semanas"), é respondido: "Mas justamente. Se você está sofrendo há três semanas é porque seu problema não é urgente!" (Dodier \& Camus, 1997: 113, tradução livre).

16 Ver a definição do dicionário.

17 Sem formação médica e novos na função de segurança de hospital e de prontosocorro.

18 O que pode conseguir o paciente que manifesta seu sofrimento é ser atendido, às vezes, com mais rapidez, simplesmente para acabar com a perturbação ou a inquietação que ele cria na sala de espera.

19 Entre os quais os que remetem à categoria dos ditos 'casos psiquiátricos'.

20 Para retomar uma expressão muito ouvida, sobretudo por parte de residentes de medicina e enfermeiros.

21 Acidentes de moto, de carro, de trabalho; quedas de cavalo, na rua, no ônibus, de um lugar elevado.

22 Afora a roupa rasgada, manchas de sangue seco, o fato de mancar.

23 A separação das competências médicas em especialidades, dentro do pronto-socorro, revela-se problemática em termos de atendimento, pois geralmente os médicos só atendem os casos que dizem respeito à sua especialidade. Quem não é pediatra não olha criança (ver o caso do neném que 'virou os olhos'); quem não é ortopedista ignora os pacientes que estão com um problema classificado pelas recepcionistas como sendo da ortopedia etc. Chega-se assim a situações, como a descrita, em que médicos e residentes desocupados e disponíveis não atendem porque o caso não diz respeito à sua especialidade ou ao estágio por especialidade que estão fazendo no pronto-socorro. A pertinência de uma interpretação tão rígida da atuação por especialidades mereceria ser interrogada dentro de uma perspectiva de melhora no atendimento.

24 Esse episódio representou um dos momentos em que duvidei de conseguir a distância necessária à realização de um trabalho de campo no pronto-socorro. 